Document downloaded from:

http://hdl.handle.net/10251/50235

This paper must be cited as:

Sellés Cantó, MA.; Schmid, S.; Reig Pérez, MJ.; Sanchez-Caballero, S.; Pérez Bernabeu, E. (2012). Upper-bound modelization of an ironed three-layered polymer-coated steel strip. International Journal of Advanced Manufacturing Technology. 60:161-171. doi:10.1007/s00170-011-3584-z.

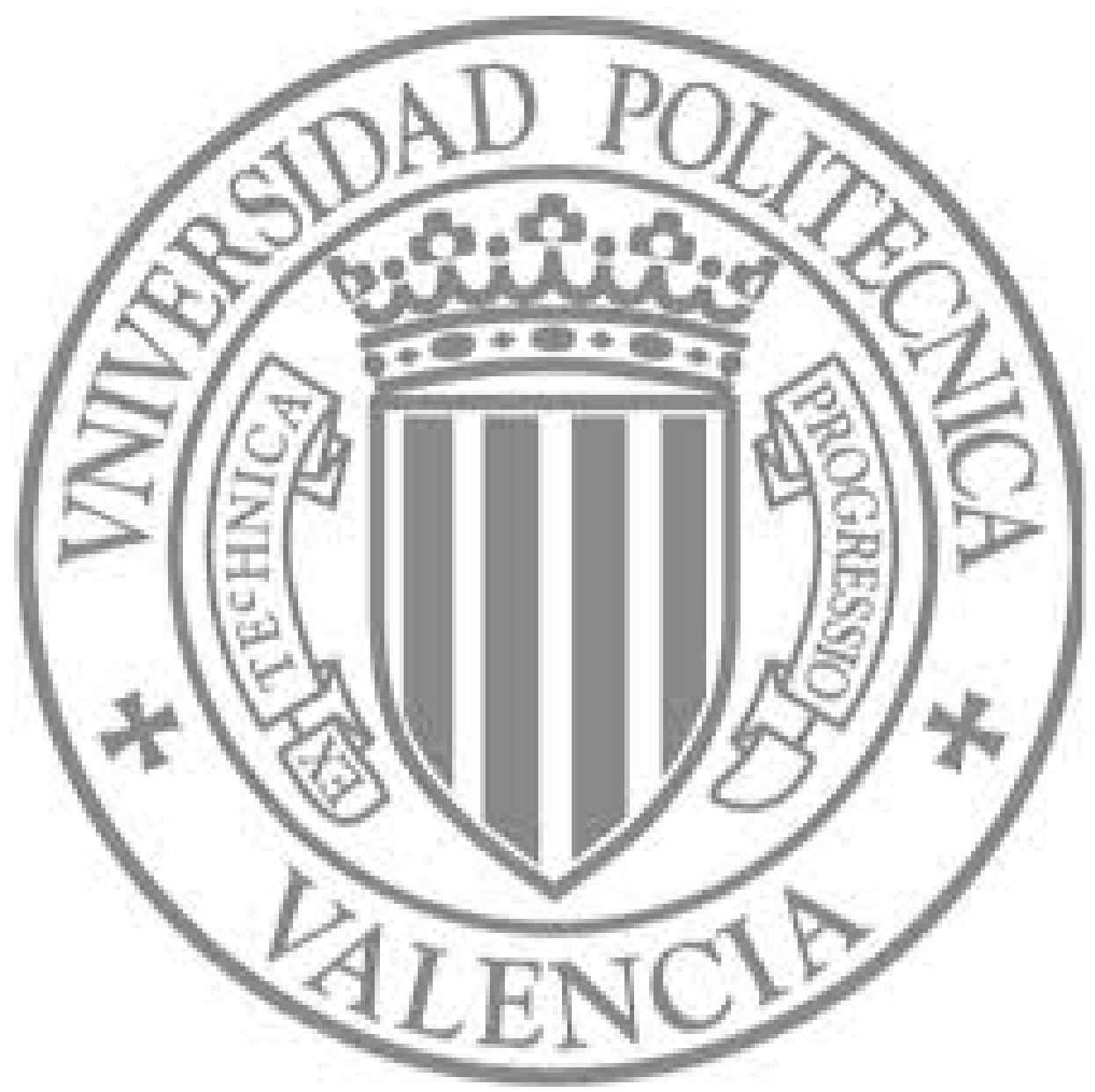

The final publication is available at

Copyright

Springer Verlag (Germany) 


\title{
Upper-Bound modelization of an ironed three-layered polymer coated steel strip
}

\author{
M.A. Selles · S.R. Schmid • M.J. Reig - S. Sanchez-Caballero • E. \\ Perez-Bernabeu
}

\begin{abstract}
Global beverage can and food container consumption is very high, with billions of cans produced annually worldwide. There are several steps in can manufacturing, but ironing is the most crucial. In a previous work [1], a series of ironing experiments were reported using a new material and an ironing simulator. This material was a three-layered polymer coated steel, and it was seen that under some process conditions, it survived the ironing process with no damage in any of the three layers. The critical die angle was determined as well as specimen quality surface tests.
\end{abstract}

In this paper, an associated theoretical ironing model is described, using the Upper Bound Theorem, and considering the cases of successful ironing or shaving. It's possible to give insight into how to design a material that irons well. For example, the optimal layer thicknesses are also found.

Keywords Ironing · Polymer coated steel · Can forming · Sheet metal forming - Upper Bound Method

M.A. Selles · M.J. Reig

Instituto de Tecnología de Materiales, Universidad Politécnica de Valencia, Plaza Ferrándiz y Carbonell s/n, 03801 Alcoy, Spain

E-mail: maselles@dimm.upv.es

S.R. Schmid

University of Notre Dame, Department of Aerospace and Mechanical Engineering, Notre Dame, IN 46556, USA

S. Sanchez-Caballero

Instituto de Diseño y Fabricación, Universidad Politécnica de Valencia, Plaza Ferrándiz y Carbonell s/n, 03801 Alcoy, Spain

E. Perez-Bernabeu

Dep. de Estadística e Investigación Operativa Aplicadas y Calidad, Universidad Politécnica de Valencia, Plaza Ferrándiz y Carbonell s/n, 03801 Alcoy, Spain

\section{Introduction}

The can manufacturing industry is of enormous scale worldwide. Every small process modification in can manufacturing can have a significant impact in the cost per can, which is calculated to a precision of millionths of dollar per can.

The metal forming processes for producing most of the food and beverage containers uses the following steps: blanking, deep drawing, redrawing, ironing, doming, necking and seaming [1]. In between the doming and necking operations, the cans are placed in a wash/coat process which removes the residue lubricants from metal forming and applies a base coating to the metal. The cans are then sprayed to present a suitable surface for food contact. The spray often consists of a polymer resin suspended in a carrier, which is then boiled off as a volatile organic compound (VOC). This is a significant environmental and health concern.

An alternative to the traditional manufacturing process is to use a polymer-layered pre-coated steel base stock. With this material it is possible to eliminate the VOCs in can manufacturing, and the polymer layers can serendipitously act as solid lubricants. Jaworski and Schmid [2] and Jaworski et al. [3] investigated such polymer-coated steels and found them to be suitable for ironing under carefully controlled conditions.

Sellés et al [1] used the same ironing simulator for experiments on a new multi layered polymer laminated material, which has the following characteristics:

- The polymer bonded to the steel can be selected to maximize adhesion at this interface.

- The exterior surface can incorporate desired permeability to aid in decoration. This is beneficial in that liquid inks will apply better to such exterior 
surfaces, will resist smearing, and will allow better resolution of decorations.

- Mechanical properties of the mid layer can be modified to increase formability.

- The thickness of each layer can be tuned to attain desired design objectives.

The results obtained with this material demonstrated that it was possible to achieve good ironing under controlled process parameters, with the critical die angle as the most important variable.

This paper describes the theoretical model of the ironing process, using the Upper Bound Method (UBM), and considering the cases of successful ironing or shaving.

\section{Literature review}

The first patent which contained the principles of ironing was taken out in the USA as early as 1904 [4], however, intensive research into this procedure around the world took place only after 1950. Most related theoretical models are based on the elementary theory of plasticity, but also on the deformation work method, the UBM, slip-line theory, multifactorial planning method and the Finite Element Method (FEM). The two methods most used are FEM and UBM.

Chang [5] uses the Lower Bound Method (LBM) for modeling the deformation of an isotropic material, without any coating. At the same time, he uses the UBM for redundant work analysis. Equations for the wall tension and the ironing force were derived. The predictions of the ironing force showed good agreement with experimental measurement data published by Huang et al [6].

Teodosiu et al [7] used FEM to model can manufacture. They used a "time-marching" scheme for their formulations, that is, targeting to a solution by increasing a variable. Practically all the steps in can manufacturing were modelled, but not for a coated material.

Zhan and Wang [8] adopted a rigid-plastic FEM to analyze the steady-deformation of extrusion and ironing, and to optimize the semi-cone angle of the extrusion die, according to the principle of minimal deformation force. They analyzed the optimal die curve for the ironing process, modelling it by several increments. It was found to correlate well to the experimental results. These results showed that the strain rate changed a great deal in the corners of the die (especially at the exit) for the processes of extrusion and ironing, and that in order to protect the workpieces from producing dead metal zones there should be a larger arc in the corner.
A one-layer polymer coated metal sheet was used by Van den Bosch et al [9] for experimental investigation of polymer coating delamination during deep-drawing. They used an axisymmetric finite element model to simulate this process and to predict the loss of adhesion of the polymer coating. The radius of the die was an important parameter and had substantial influence on the interfacial integrity. The radius of the punch, on the other hand, had only a minor influence. An increase of the coating thickness led to a minor decrease of the interfacial integrity.

Schünemann et al [10] worked with FEM techniques in order to predict process conditions in can ironing. They did multi stage ironing simulations with the commercial code DEFORM to check the model, considering two aluminum alloys, without any polymer layer on the metal base. It was seen that the most crucial ironing step was the first one.

The model created by Jaworski and Schmid [2] assumed that the polymer was fully bonded to the substrate, that is, the interface strength was equal to the shear strength of the polymer film. Their mathematical model confirmed from minimum energy principles that ironing would be successful at low die angles, and shaving would be the result from higher die angles.

Van der Aa et al [11] used FEM to simulate the wall ironing of polymer coated sheet metal. An advanced constitutive equation was used to describe elasto-viscoplastic polymer material behaviour. They verified their results with a plane strip ironing set-up. For both experimental and numerical results, they found that shear deformation occurs in the aluminum sheet metal rather than in the polymer coating, which apparently only reduces thickness.

Nilsson and Legge [12] used FEM for aluminum ironing. According to their simulations, the process is relatively insensitive to changes in the punch radius.

Kampus and Nardin [13] used the theory of plasticity to model the ironing process, producing an ironing workability diagram to describe the stress-strain state.They applied this model to production of cups with non-uniform wall thickness, using a FEM model. The theoretical model and experiments showed that the maximum strain can be increased by up to $40 \%$ with the use of a superimposed force.

Wang et al [14] simulated surface smoothing in the ironing process by elasto-plastic FEM. Variations of contact pressure, ironing reduction, plastic strain and die angle were analyzed. They also made a comparison between surface roughness and ironing reduction, and found that with increases in the ironing reduction, the asperity smoothing is promoted and at about $\mathrm{Re}=20 \%$, 
asperities could be observed to be completely smoothed.

Deneuville and Lecot [15] combined the use of strip ironing experiments and a FEM program to obtain friction coefficients for the die surface, punch surface and land zone. The experimental/numerical approach resulted in a powerful analysis tool for the wall ironing process.

Table 1 shows a summary of the theoretical studies in chronological order, considering the theoretical model used and if this has been applied to a coated material. It can be seen that only three studies have worked with a coated sheet metal. No previous research has addressed the effect of three polymer layers on a metal substrate.

\section{Model considerations}

A theoretical model will serve to make predictions on the possible ironing success using multi-layered polymer steel coatings. As shown before, FEM is the modeling method used most by researchers. However, FEM is difficult to use for predictive models. Some researchers prefer the UBM. The UBM is also quick, generic and can accurately model the real process.

As described by Hosford and Caddell [16], the UBM assumes a kinematically admissible flow field in which the material undergoes the necessary deformations required to obtain the final shape.

In using UBM for metal forming processes, it is often convenient to assume that the problem is in a plane strain condition, reducing it to two dimensions, which in this case correlates to strip ironing as in the experimental analysis [1]. Further, the workpiece is assumed to be a rigid, perfectly plastic material, and strain rate effects are ignored. In practice, these effects can be incorporated by defining an effective flow stress that depends on the constitutive model, including the polymer's pressure-sensitive shear strength. For example, for a power law material, the specific energy can be expressed as:

$u=\frac{K \epsilon^{n+1}}{n+1}=\bar{Y} \epsilon$

Solving for the effective flow stress, $\bar{Y}$ yields:

$\bar{Y}=\frac{K \epsilon^{n}}{n+1}$

where $K$ is the strength coefficient and $n$ is the strainhardening exponent. The effective shear strength is onehalf this flow strength according to the Tresca yield criterion or 0.577 times this flow strength according to the von Mises criterion.
The main shortcoming with the UBM is that displacements need to be known or assumed a priori. This is usually overcome by obtaining candidate fields from slip line theory, from experimental evidence, or from simple intuition.

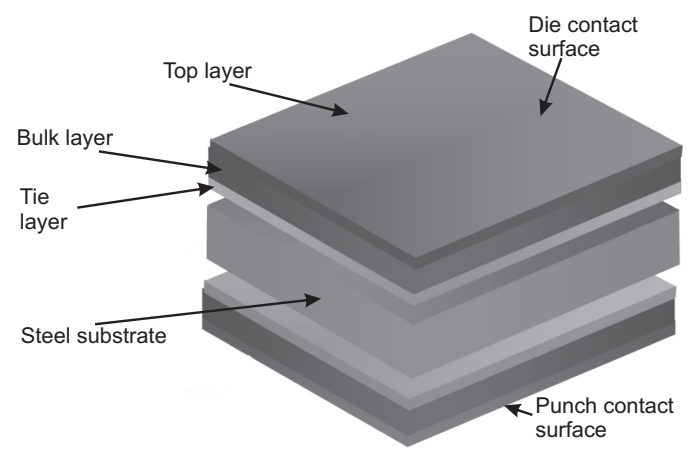

Fig. 1 3D image of layer distribution in the material used.

\subsection{Material parameters}

Different polymer layers are used as steel coatings, and they are only useful if integrity is maintained during can manufacturing: any polymer shaving can result in can corrosion and damage to the food or beverage.

As mentioned in many documents related with can manufacturing, ironing is the most critical step for polymer survivability. In ironing, the pressures are extremely large, the strains and strain rate are very high, and new surface is manufactured from the sheet bulk.

An image of the new three-layered polymer coated steel is illustrated in Figure 1 and has the following characteristics:

- A three-layer system can be placed on both the die sides and punch of the sheet.

- The layer bonded to the metal substrate is referred to as the tie layer, followed by the bulk layer and finally the top layer. A typical thickness ratio for the tie/bulk/top layers is $1: 3: 1$, with typical overall thickness of $12.5-35 \mu \mathrm{m}$.

- The layers can be adjusted to meet specific customer requirements.

There is significant flexibility in formulating this material, and many combinations of chemical and mechanical properties can be achieved. The layers can be adjusted to meet specific customer requirements. The following can be described as a typical formulation:

1. The tie layer as a maleic anhydride polypropylene. 


\begin{tabular}{lccccc}
\hline Author & Year & $\begin{array}{c}\text { FEM } \\
\text { Model }\end{array}$ & $\begin{array}{c}\text { UBM } \\
\text { Model }\end{array}$ & $\begin{array}{c}\text { Coated } \\
\text { Material }\end{array}$ & $\begin{array}{c}\text { Number of } \\
\text { layers }\end{array}$ \\
\hline Deneuville & 1994 & Yes & No & No & 0 \\
Teodosiu & 1995 & Yes & No & No & 0 \\
Zhan & 1995 & Yes & No & No & 0 \\
Schünemann & 1996 & Yes & No & No & 0 \\
Van der Aa & 1998 & Yes & No & Yes & 1 \\
Chang & 1998 & No & Yes & No & 0 \\
Nilsson & 1999 & Yes & No & No & 0 \\
Jaworski & 1999 & No & Yes & Yes & 1 \\
Wang & 2001 & Yes & No & No & 0 \\
Kampus & 2002 & Yes & No & No & 0 \\
Van den Bosch & 2009 & Yes & No & Yes & 1 \\
Present work & 2011 & No & Yes & Yes & 3 \\
\hline
\end{tabular}

Table 1 Literature table on theoretical studies in chronological order.

2. The bulk layer as a combination of polybutene and a random copolymer (RACO).

3. The top layer can consist of a combination of silicon in polyproplylene homopolymer, polybutene and a random copolymer.

\subsection{Variables}

It is important to recognize the variables involved in ironing, in order to build a good theoretical model. The variables considered are: die angle, thickness reduction, punch velocity, the material and temperature.

If the material changes, the friction factors with the die and the punch and the material change. So this factor will change for every different material used.

When a high temperature is applied to a material, this usually changes its structure. For metals, this temperature is higher than can be survived by polymers. When working with a thermoplastic coated material, the temperature applied should be above the glasstransition but below the melting temperature. When the temperature is between these two values, the polymer ductility is high, as is its lubrication ability [17].

When the reduction occurs, the gap between the die and the workpiece is reduced. The contact surface between these two elements increases if the die angle increases. The pressure applied to the workpiece by the die in the small space is almost independent of the die angle, and therefore, the force increases with the contact surface [16].

Finally, the punch speed, which is directly proportional to the power, is a fundamental variable for the speed calculation using the discontinuity fields [18].

\subsection{Energy considerations}

In order to determine the required loads for plastic deformation, the internal energy consumed in the process is needed. This energy is found via the power expended along velocity discontinuities, both shear and frictional. Power can be defined by

$P=F v$,

where $F$ is force and $v$ is velocity. As a result, the power expended on each discontinuity can be determined by the force, shear or friction, and the relative velocity along that plane. The shear force can be expressed as

$F_{s}=\tau A$,

where $\tau$ is the shear stress along the plane, and $A$ is the area of the plane. However, since the material is yielding, $\tau$ is the shear yield stress of the material denoted as $k$, and $A$ can be replaced by $l w$, where $l$ is the length of the plane, and $w$ is its width. Thus, Equation 4 becomes

$F_{s}=k l w$,

The frictional force between dissimilar materials may be expressed as a variation of the shear force. Kalpakjian [19] describes how Coulomb friction is no longer accurate at high loads, such as those experienced in metal forming operations like ironing. Localized asperity contact in a metalworking interface is characterized by an adhesive bond between the surfaces. For high load situations, these bonds form microwelds, and the interface has a shear strength, $\tau_{i}$.

In ironing, the relative motion between the surfaces leads to a surface shear stress [16] and will decrease the 
value of the normal stress under which plastic deformation of the asperities will occur. In such circumstances, the Tresca [20] friction model is appropriate,

$F_{f}=m k A_{a}=m k l w$

where $m$ is the friction factor which indicates the degree of adhesion at every interface, expressed as some constant proportion of the softer material's shear strength, $k$; and $A_{a}$ is the contact area between both surfaces $\left(A_{a}=l w\right)$.

A value of $m=0$ indicates frictionless conditions, while $m=1$ indicates total adhesion between the sliding materials, and in essence the frictional plane becomes one of shear. Power dissipated on a frictional or shear plane is then either

$P_{f}=F_{f} v=m k l w v$

or

$P_{s}=F_{s} v=k l a v$,

where $v$ is the relative velocity along that plane between adjacent regions.

The discontinuity lengths, $l$, in Equations 7 and 8, are determined from the velocity discontinuity field geometry using trigonometric relations. The relative velocities, $v$, in Equations 7 and 8 are determined from the hodograph.

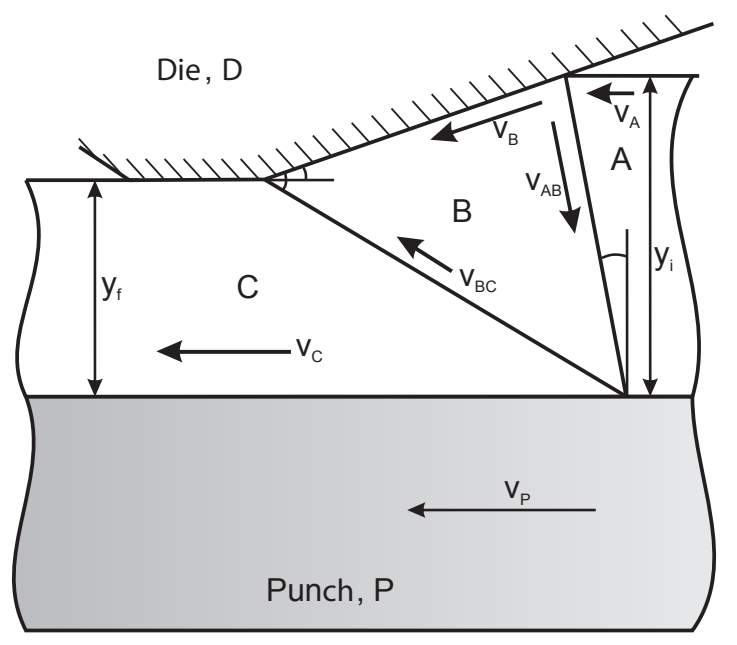

Fig. 2 Velocity discontinuity field for uncoating ironing.

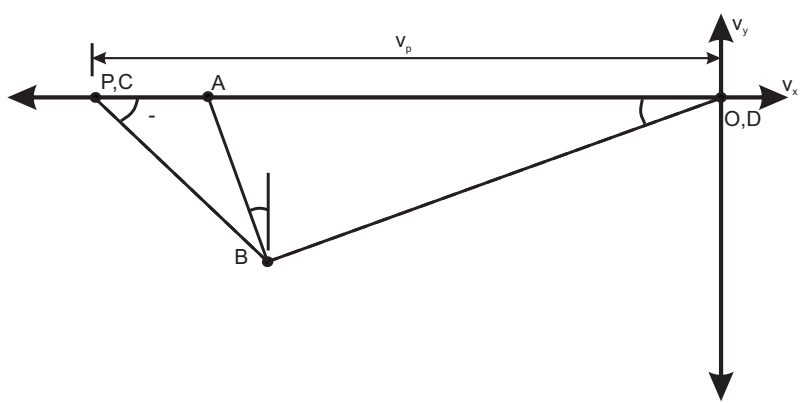

Fig. 3 Final hodograph for Figure 2.

For example, consider Figures 2 and 3 where the difference in velocity on the common boundary of regions $\mathrm{C}$ and $\mathrm{B}$ is depicted by the line $\mathrm{CB}$ on the hodograph, since points $\mathrm{C}$ and $\mathrm{B}$ represent the respective velocities of those regions. The magnitude of this velocity difference is simply the length of the line CB, which is calculated proportional to a known value, in this case the punch velocity $v_{p}$, using trigonometry. The total dissipated power for the flow field is then given by

$P_{\text {total }}=\sum_{i} P_{c_{i}}+\sum_{j} P_{f_{j}}$

where $i$ is the number of shear planes, and $j$ is the number of frictional planes. The first term in Eq. 9 can be considered to be the sum of the internal power dissipated and the redundant work, and the second term the power dissipated by friction. Conservation of energy will then yield the required input power.

\subsection{Mathematical procedure}

As discussed above, the required input power determined by Equation 9 will, by the UBM, be greater than the exact load solution. Minimization of the power expression will lead to a solution which approaches the exact one.

One of the main drawbacks of using an UBM is that the deformation field is assumed to have a specific geometry a priori. This geometry governs much of the accuracy of the model. Yet there is no way to know the correct field, and a trial and error approach must be used to find the optimum result.

Two programs have been developed for comparison using the UBM, with optimization techniques from $\mathrm{H}$. Press [21]. The power function is smooth and absent of local minima and maxima, and no unusual difficulties are encountered in their minimization.

Equations from the velocity discontinuity fields and hodographs have been programed, as well as power calculations. 


\section{Modelling}

For the present research, two possible results have been considered as consequence of ironing, both of which have been observed experimentally: successful ironing and shaving. For shaving, the workpiece is damaged and may not be appropriate. The steel base is coated by three polymer layers, and if the workpiece is damaged in the ironing, one of these consequences will occur:

- Damage only at the top polymer layer.

- Damage at both top and bulk polymer layers.

- Damage at the three polymer layers.

Two models have been developed using the UBM: one for successful ironing and the another one in case of shaving. The power needed to damage the tie and bulk layers is always higher than the power needed to produce damage at the top layer. For this reason this paper only consider the case where damage is produced at the top layer. This simplification is consistent with experimental observations for the materials and reductions considered. If a different layered structure is considered where the top and structural layers have different strengths (especially if the top layer is stronger than the structural layer), then this simplification would no longer be valid and all failure modes would need to be considered.

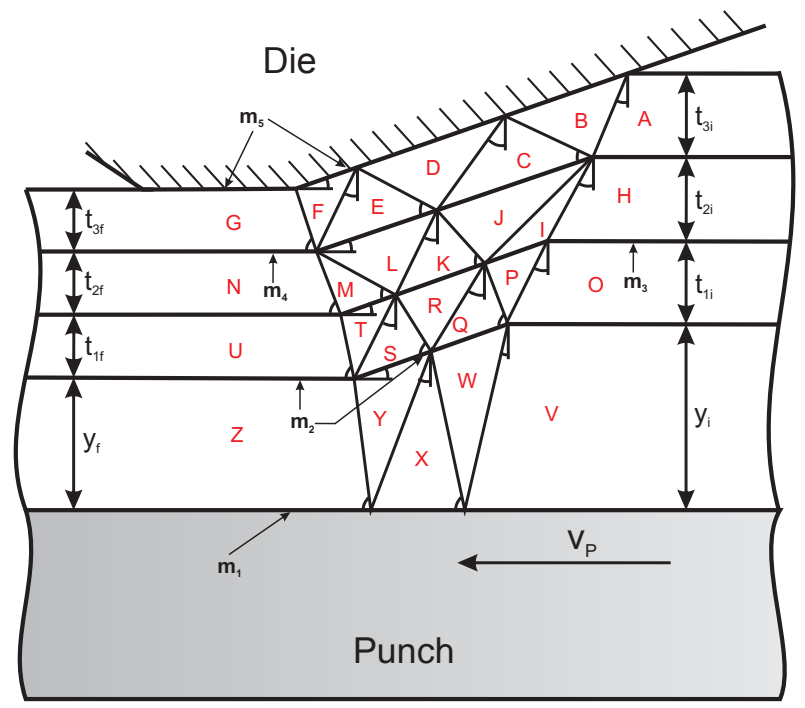

Fig. 4 Velocity discontinuity field for successful ironing condition.

The two corresponding UBM's developed incorporate some simplifying assumptions. As discussed above, both the coatings and workpiece are assumed to have no strain hardening or strain rate effects, and sticking fric- tion and plane strain conditions are invoked. The materials are considered rigid, perfectly plastic solids with constant shear strengths, which is necessary for deformation to occur in well defined shear planes. However, a polymer seldom behaves as a perfectly plastic material, nor does it typically deform along discrete planes. However, it is felt that the use of a reasonable number of shear planes will improve the accuracy of the power estimates. In addition, an effective shear strength can be assumed for a polymer, as discussed by Challen et al [22], to permit a more accurate application of a rigid, perfectly plastic model, which assumes a constant strength. This effective strength is defined as

$\bar{k}=\frac{1}{\gamma_{t}} \int_{0}^{\gamma_{t}} k(\gamma) d \gamma$

where $\bar{k}$ is the effective shear strength, $\gamma_{t}$ is the total shear strain and $k$ is the shear stress. In the models presented, the coating effective shear strength, $k_{i}$, is specified as fraction of the workpiece shear strength, $k_{p}$.

Each frictional interface in the system has a unique friction factor. The workpiece-punch interface is characterized by $m_{1}$, the steel-tie layer interface by $m_{2}$, the tie-bulk layers interface by $m_{3}$, the bulk-top layers interface by $m_{4}$, and finally, $m_{5}$ represents the friction in die-top layer interface.

Since experiments have demonstrated that the coating on the punch side always survives the ironing process, it will be ignored and the case where a polymer coating exists only on the die side will be considered. This can be seen to have no effect on formability studies of the die side, since a surviving polymer coating on the punch side merely adds a constant value of power, which has no effect when the power is minimized. For the same reason, no power has been calculated for the metal substrate. However, for an accurate model of ironing force, these contributions would need to be incorporated.

\subsection{Ironing model}

Figure 4 depicts a velocity discontinuity field for successful ironing using a three-layer polymer coated steel. The diagram is not to scale, and friction factors remain as defined above. Plane G-Die is assumed to exist along the entire land length.

The deformation planes in the polymer layers and workpiece are functions of the variable angles $\alpha_{1}$ through $\alpha_{10}$, and $\beta_{1}$ through $\beta_{11}$, as well as specified values of reduction and of $\phi, \mu, \tau$ and $\gamma$ angles. Since there is no evidence of delamination of the polymer layers, it is assumed that each layer encounters the same 


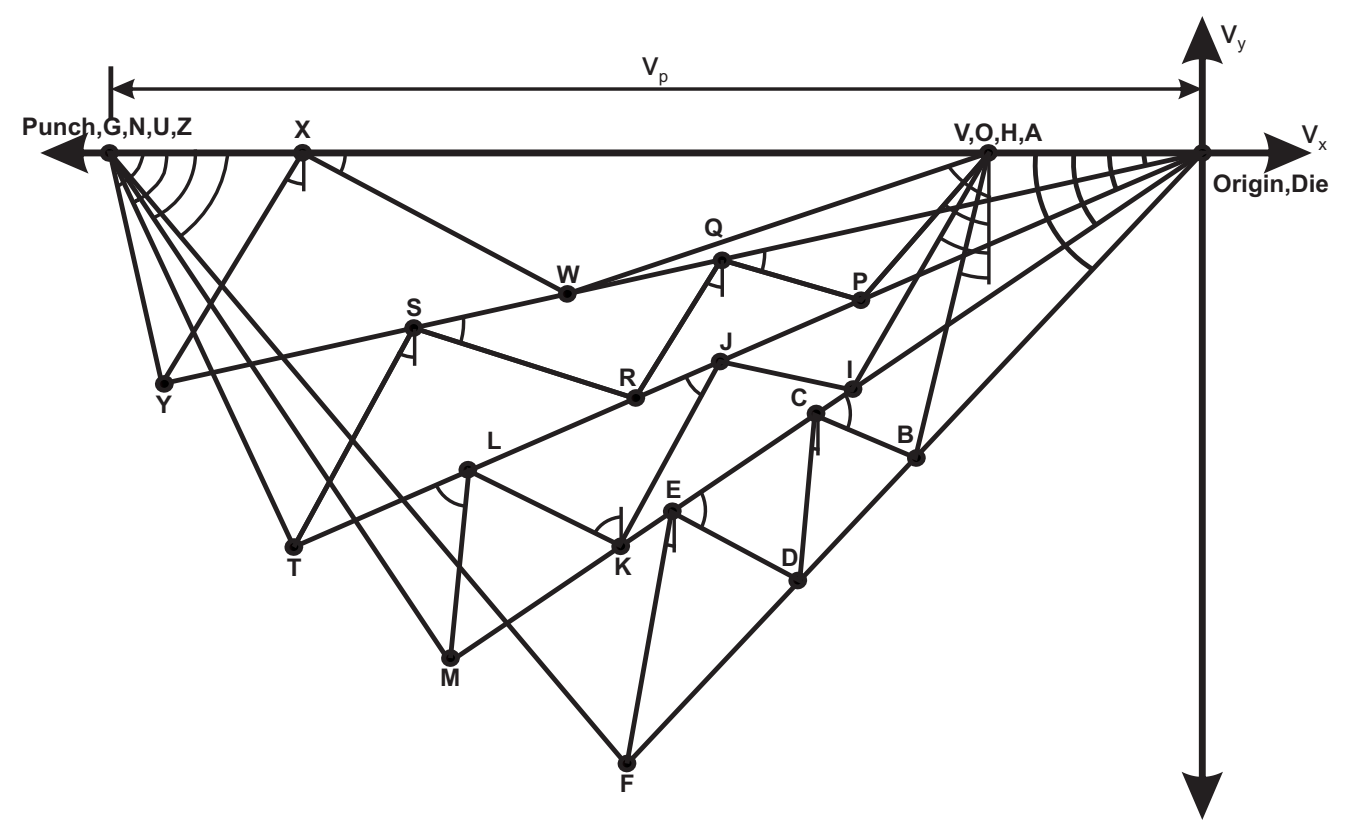

Fig. 5 Hodograph for successful ironing condition.

reduction in thickness. As can be seen, the angles in region borders with the vertical are represented with $\alpha$. $\phi$ is the die angle. Angles $\mu, \tau$ and $\gamma$ are given by the horizontal and every polymer layer.

The angles characterizing the geometry of the velocity discontinuity field are present in the hodograph shown in Figure 5, where all the considered angles can be seen.

Figure 6 depicts the non-dimensional power curves for the successful ironing model. As can be seen, an increase in reduction requires an increase in power. At the same time, power also increases with die angle.

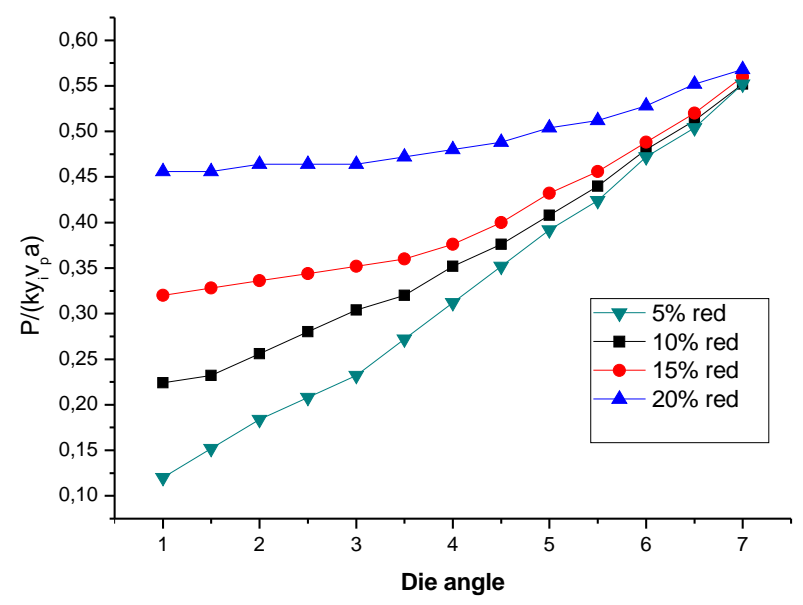

Fig. 6 Non-dimensional power versus die angle for varying reduction in a successful ironing condition.

\subsection{Shaving model}

There are many consequences of incorrect ironing, and one of them are removal or damage in different layers. If shaving is produced only in the top layer, this condition will require less power than if produced in other deeper layers. Therefore, the shaving model will only consider this case.

Figure 7 shows a velocity discontinuity field class for shaving of a three-layer polymer coated steel.

Region D is the saved polymer coating, and its final thickness is equal to its initial thickness. The actual area of contact between this layer and the die is difficult to calculate, so an approximation is used. This contact length between D and Die is shown in Figure 7, following an approach used by Wilson and Halliday [23]. The contact occurs on the projection of the shear plane on the Die.

The resulting velocity hodograph for the shaving condition is shown in Figure 8. It's important to mention that region $\mathrm{C}$ is stationary [3].

Figure 9 shows the power curves for the shaving model for varying initial coating thickness. An increase in coating thickness increases the dissipated power. However, this power decreases as the die angle becomes larger. 


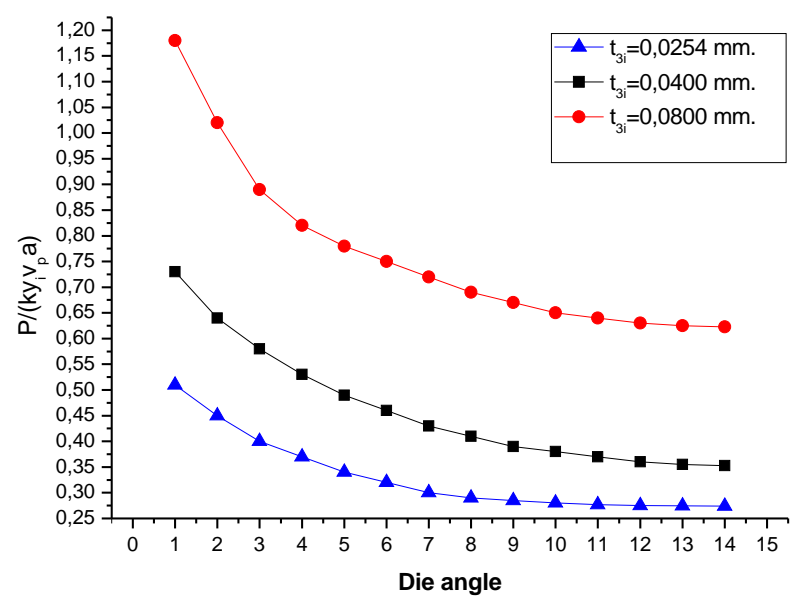

Fig. 9 Non-dimensional power versus die angle for varying coating thickness, if shaving model is used.

\section{Results}

The two models developed allow simple material formability analysis in ironing. Non-dimensional power curves (such as power vs. die angle, power vs reduction, etc) can be obtained easily, by specifying the necessary material and process parameters, and optimizing Equation 9. Results are different depending on the model used: successful ironing or shaving. The UBM states that the actual process will follow the deformation mode which requires less power dissipation. Comparison of power curves for each model indicates which is the preferred mode under certain conditions.

In the following results, process input power has been non-dimensionalized in the form $P / k a y_{i} v_{p}$, whenever possible, where $P$ is power, $k$ is workpiece shear strength, $a$ is strip width, $y_{i}$ is the initial workpiece thickness and $v_{p}$ is the punch velocity. Process geometry can be varied according to the available inserts.

Figure 10 contains a comparison of optimized power curves versus die angle for the shaving and successful ironing conditions, for an arbitrary set of process parameters. One can see that below a certain angle, in this case $\phi \approx 4^{\circ}$, successful ironing will require less power, hence be the preferred mode, by the UBM. Above this angle, shaving will require less power. This critical angle, $\phi_{c}$, is of great interest from a formability standpoint, as it will dictate the tooling geometries which would be feasible for three-layered polymer coated ironing.

Figure 11 depicts the critical die angle determined with the UBM models, for a reduction of $10 \%$. Friction factors are set as $m_{1}=1, m_{2}=m_{5}=0.03$ and $m_{3}=m_{4}=0.9$. With these settings, the critical die angle arises at $\phi_{c}=6.7^{\circ}$. The estimation of

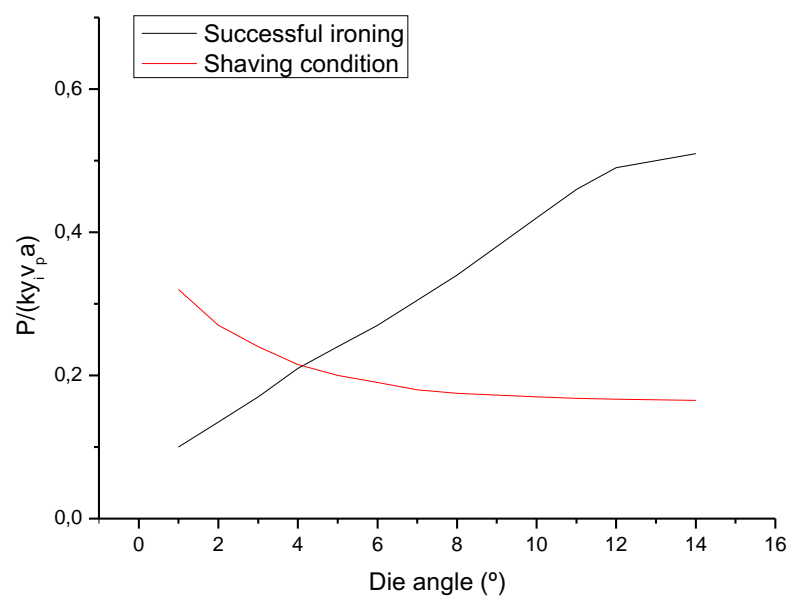

Fig. 10 Optimized shaving and successful ironing curves vs. die angle.

these friction factors has been done using the results obtained by Jaworski et al [3], in which the friction between the polymer and the die has been measured to be very low, and this has been the basis for the low polymer/tooling friction. Between polymer layers, it is assumed that the friction is high because of the good bond strength developed during the lamination process. Between the workpiece and punch, friction can be controlled and can achieve a high or low value depending on punch surface preparation. However, the results are insensitive to polymer/punch friction since it is always present and therefore provides a constant to the power equation, which has no effect in minimization.

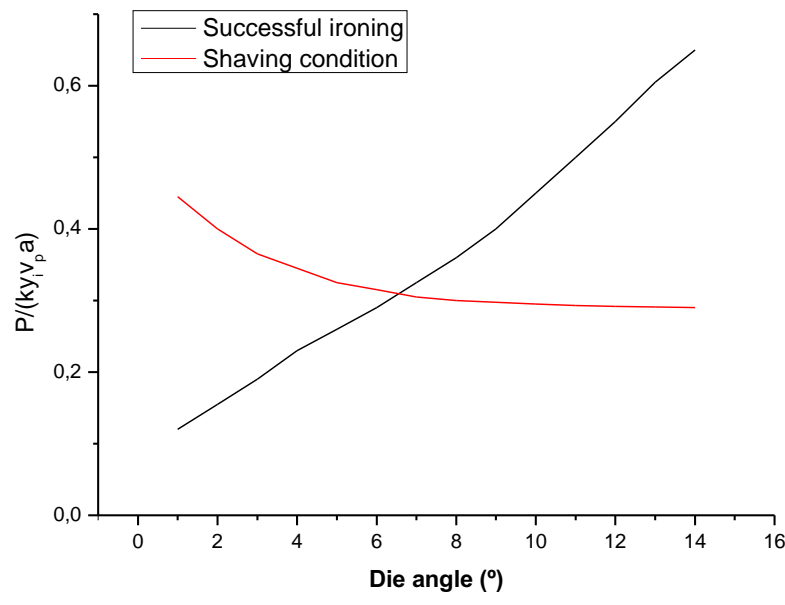

Fig. 11 Power curves for both models. Parameters are as follows: $\%_{\text {red }}=10 \%, y_{i}=0.254 \mathrm{~mm}, t_{1 i}=t_{3 i}=0.0254 \mathrm{~mm}, t_{2 i}=$ $0.0762 \mathrm{~mm}, k_{m}=1.53 k_{p}, m_{1}=1, m_{2}=m_{5}=0.03, m_{3}=$ $m_{4}=0.9$. 


\begin{tabular}{|c|c|c|c|c|}
\hline \multicolumn{7}{|c|}{} & Value & Value & Value & Value \\
\hline Power & 7234.56 & 256743.32 & 287654.89 & 310844.12 \\
\hline$\alpha_{1}$ & 20.294 & 28.210 & 18.455 & 30.765 \\
\hline$\alpha_{2}$ & 18.234 & 27.634 & 17.465 & 26.973 \\
\hline$\alpha_{3}$ & 36.610 & 46.772 & 32.344 & 49.654 \\
\hline$\alpha_{4}$ & 23.055 & 31.856 & 24.523 & 38.452 \\
\hline$\alpha_{5}$ & 24.565 & 33.788 & 26.345 & 30.132 \\
\hline$\alpha_{6}$ & 35.331 & 43.898 & 33.465 & 52.322 \\
\hline$\alpha_{7}$ & 30.008 & 38.354 & 32.560 & 44.452 \\
\hline$\alpha_{8}$ & 27.703 & 33.653 & 33.237 & 39.675 \\
\hline$\alpha_{9}$ & 22.977 & 26.766 & 28.455 & 33.820 \\
\hline$\alpha_{10}$ & 32.867 & 38.776 & 29.648 & 43.895 \\
\hline$\beta_{1}$ & 37.935 & 45.890 & 41.566 & 48.520 \\
\hline$\beta_{2}$ & 33.856 & 41.663 & 36.575 & 46.233 \\
\hline$\beta_{3}$ & 38.890 & 48.980 & 42.455 & 49.566 \\
\hline$\beta_{4}$ & 36.898 & 46.364 & 38.955 & 52.510 \\
\hline$\beta_{5}$ & 29.344 & 37.533 & 34.565 & 39.789 \\
\hline$\beta_{6}$ & 42.587 & 48.865 & 40.532 & 51.465 \\
\hline$\beta_{7}$ & 28.207 & 32.467 & 36.578 & 35.876 \\
\hline$\beta_{8}$ & 24.170 & 29.677 & 26.855 & 30.008 \\
\hline$\beta_{9}$ & 38.661 & 43.521 & 42.956 & 48.590 \\
\hline$\beta_{10}$ & 42.622 & 51.234 & 45.988 & 56.280 \\
\hline$\beta_{11}$ & 36.446 & 57.677 & 38.341 & 59.735 \\
\hline$\phi$ & 0.5 & 0.5 & 7 & 7 \\
\hline$\mu$ & 0.844 & 0.566 & 0.932 & 0.673 \\
\hline$\tau$ & 0.552 & 0.678 & 0.896 & 0.734 \\
\hline$\gamma$ & 0.664 & 0.664 & 0.765 & 0.798 \\
\hline$y_{f}$ & 0.2413 & 0.1905 & 0.2413 & 0.1905 \\
\hline$y_{1 f}$ & 0.0241 & 0.0190 & 0.0241 & 0.0190 \\
\hline$y_{2 f}$ & 0.0723 & 0.0506 & 0.0723 & 0.0506 \\
\hline$y_{3 f}$ & 0.0241 & 0.0190 & 0.0241 & 0.0190 \\
\hline$y_{i}$ & 0.254 & 0.254 & 0.254 & 0.254 \\
\hline$y_{1 i}$ & 0.0254 & 0.0254 & 0.0254 & 0.0254 \\
\hline$y_{2 i}$ & 0.0762 & 0.0762 & 0.0762 & 0.0762 \\
\hline$y_{3 i}$ & 0.0254 & 0.0254 & 0.0254 & 0.0254 \\
\hline & & & & \\
\hline
\end{tabular}

Table 2 Table with four simulations made using the successful ironing program. Every column is a simulation, and the values adopted for every variable are shown in arrows.

Table 2 shows the result of four simulations done with the successful ironing model. Every column is a simulation, and the values adopted for every variable are shown in arrows. Power is the output equation, and the program minimizes it to a maximum value, according to a specified constraints. The following data have been used for the previous simulations:

- Punch velocity $\left(v_{P}\right)=1 \mathrm{~m} / \mathrm{s}$

- Strip width $(a)=16 \mathrm{~mm}$

- Friction factor $m_{1}$ (Punch-Substrate interface $)=1$

- Friction factor $m_{2}$ (Substrate-Tie layer interface $)=$ 0.03

- Friction factor $m_{5}$ (Die-Top layer interface $)=0.03$

- Friction factor $m_{3}$ (Tie layer-Bulk layer interface)= 0.9

- Friction factor $m_{4}$ (Bulk layer-Top layer interface)= 0.9

- Polymer shear strength $\left(k_{p}\right)=0.5 \mathrm{MPa}$

- Steel substrate shear strength $\left(k_{m}\right)=1.53 k_{p} \mathrm{MPa}$

- Polymer top layer initial thickness $\left(y_{3 i}\right)=0.0254$ $\mathrm{mm}$

- Polymer bulk layer initial thickness $\left(y_{2 i}\right)=0.0762$ $\mathrm{mm}$

- Polymer tie layer initial thickness $\left(y_{1 i}\right)=0.0254 \mathrm{~mm}$

- Steel substrate initial thickness $\left(y_{i}\right)=0.254 \mathrm{~mm}$

The mathematical model allows variation of all of these parameters, and can be used as a design tool. Note that the results presented use the values given. For example, the polymer is approximately one-third

\begin{tabular}{|c|c|c|c|}
\hline & $10 \%$ Reduction & $20 \%$ Reduction & $30 \%$ Reduction \\
\hline Top layer & $0,013 \mathrm{~mm}$ & $0,023 \mathrm{~mm}$ & $0,027 \mathrm{~mm}$ \\
Bulk layer & $0,019 \mathrm{~mm}$ & $0,041 \mathrm{~mm}$ & $0,046 \mathrm{~mm}$ \\
Tie layer & $0,028 \mathrm{~mm}$ & $0,069 \mathrm{~mm}$ & $0,080 \mathrm{~mm}$ \\
\hline
\end{tabular}

Table 3 Initial optimum polymer layer thicknesses versus reduction. The restriction used is that the initial thicknesses must be positive.

the strength of the steel, a value that is typical at the high forming pressures in ironing [6].

Power increases with die angle, material strength, and also with the reduction applied to the workpiece. With low die angles, Power also increases if compared with the reduction applied.

The successful ironing model also allows examination of the influence of material parameters, and it's possible to give insight into how to design a material for maximum ironability. For example, using the data shown before and a die angle of $\phi_{c}=6.7^{\circ}$, and without considering the initial polymer layers thicknesses, the program minimized Equation 9, resulting in the values shown in Table 3.

The data shown in Table 3 indicate that for a specific die angle, the optimal initial thickness is different for each reduction. But in all cases, the tie layer is thicker than the bulk layer, and this is thicker than the top one.

\section{Conclusions}

Quick predictions for material formability can be obtained using the UBM models presented. The programs can be easily modified for adapt the equations to a material with $\mathrm{n}$ polymer layers.

Formability data was obtained both through experimentation [1] and theoretical modeling with UBM. Both data was quite similar, and this indicates a good theoretical approximation. The two models correspond well with the experiments.

The critical die angle obtained through experimentation is $\phi_{c}=7^{\circ}$, while the theoretical critical die angle is $\phi_{c}=6.7^{\circ}$. Deviations between experiment and theory can be attributed to simplifying assumptions made by the models. Despite these shortcomings, the survivability demonstrated by the polymer coatings suggests that it has the ability to serve both as the forming lubricant and food contact surface for a two-piece can.

Acknowledgements The authors wish to thank Mittal Steel for financial support and for providing all required materials. Authors also thank the support of Universitat Politècnica de València [grant number PAID-06-10-003-305]. 


\section{References}

1. M.A. Sellés, S.R. Schmid, y V.J. Seguí. Ironability of a three-layereed polymer coated steel. part 1: Experimental investigation. Journal of Materials Processing Technology, 202:7-14, 2008.

2. J.A. Jaworski y S.R. Schmid. Survivability of laminated polymer lubricant films in ironing. Tribology Transactions, 1(32-38), 1999.

3. J.A. Jaworski, S.R. Schmid, y J.E. Wang. An experimental investigation of the survivability and friction characteristics of tin-coated and polymerlaminated steels. Journal of Manufacturing Science and Engineering, 121(232-237), 1999.

4. D. Campion. Deep drawing and ironing - theory and practise. Sheet metal industry, 57:111-119, 1980.

5. Der-Form Chang. An analytical model of the ironing process including redundant work effect. Journal of Materials Processing Technology, 75:253-258, 1998.

6. Y.M. Huang, Y.H. Lu, y J.W. Chan. An elastoplastic finite element and experimental study of the ironing process. Journal of Materials Processing Technology, 26:53-80, 1991.

7. C. Teodosiu, D. Daniel, H.L. Cao, y J.L. Duval. Modelling and simulation of the can-making process using solid finite elements. Journal of Materials Processing Technology, 50:133-143, 1995.

8. Z.R. Zhan y C.W. Wang. Numerical simulations for extrusion and ironing and die-angle optimization. Journal of Materials Processing Technology, 55:4852,1995 .

9. M.J. Van den Bosch, P.J.G. Schreurs, y M.G.D. Geersa. On the prediction of delamination during deep-drawing of polymer coated metal sheet. Journal of Materials Processing Technology, 209:297302, 2009.

10. M. Schünemann, M. Ahmetoglu, y T. Altan. Prediction of process conditions in drawing and ironing of cans. Journal of Materials Processing Technology, 59:1-9, 1996.

11. M.A.H. Van der Aa, P.J.G. Schreurs, y F.P.T. Baaijens. Modelling of the wall ironing process of polymer coated sheet metal. Proceedings of Fourth World Congress on Computational Mechanics, 1998.

12. A. Nilsson y D. Legge. Process development of aluminium ironing using finite element analysis. Modelling simulations at material science engineering, 7:1005-1011, 1999.

13. Z. Kampus y B. Nardin. Improving workability in ironing. Journal of Materials Processing Techno- logy, (130-131):64-68, 2002.

14. Z. Wang, K. Dohda, y Y. Jeong. Fem simulation of surface smoothing in the ironing process. Journal of Materials Processing Technology, 113:705709, 2001.

15. P. Deneuville y R. Lecot. The study of friction in ironing process by physical and numerical modelling. Journal of Materials Processing Technology, 45:625-630, 1994.

16. W. Hosford y R. Caddell. Metal Forming: Mechanics and Metallurgy. Cambridge University Press, 3 edition, 2007.

17. William F. Hosford. Mechanical Behavior of Materials, Vol. 1. Cambridge University Press, 2008.

18. Geoffrey W. Rowe. Conformado de los metales. Ediciones Urmo, 1 edition, 1972.

19. S. Kalpakjian. Manufacturing Processes for Engineering Materials. Wesley, 3 edition, 1997.

20. H. Tresca. On further application of the flow of solids. Actas Instituto de Ingeniería Mecánica, 30(301), 1878.

21. William H. Press, Saul Teukolsky, William Vetterling, y Brian P. Flannery. Numerical Recipes in $C++$, Vol. 2. Cambridge University Press, 2002.

22. J.M. Challen, L.J. Mclean, y L.B. Oxley. Plastic deformation of a metal surface in sliding contact with a hard wedge: its relation to friction and wear. $A c-$ tas de la Royal Society de Londres, 394(1806):161$181,1884$.

23. W.R.D. Wilson y K. Halliday. An inlet zone analysis for the lubrication of a drawing process by a rigid-plastic solid. Wear, 42:135-148, 1977. 


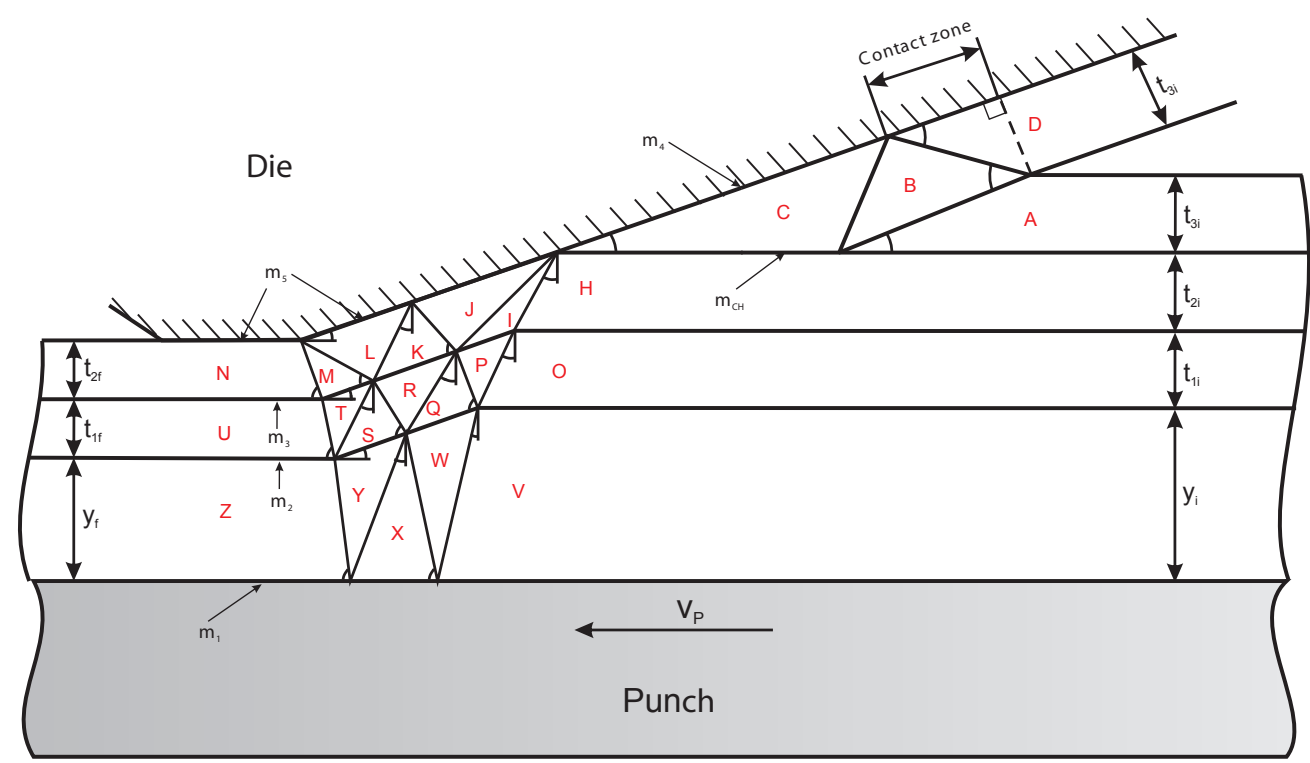

Fig. 7 Velocity discontinuity field for shaving condition.

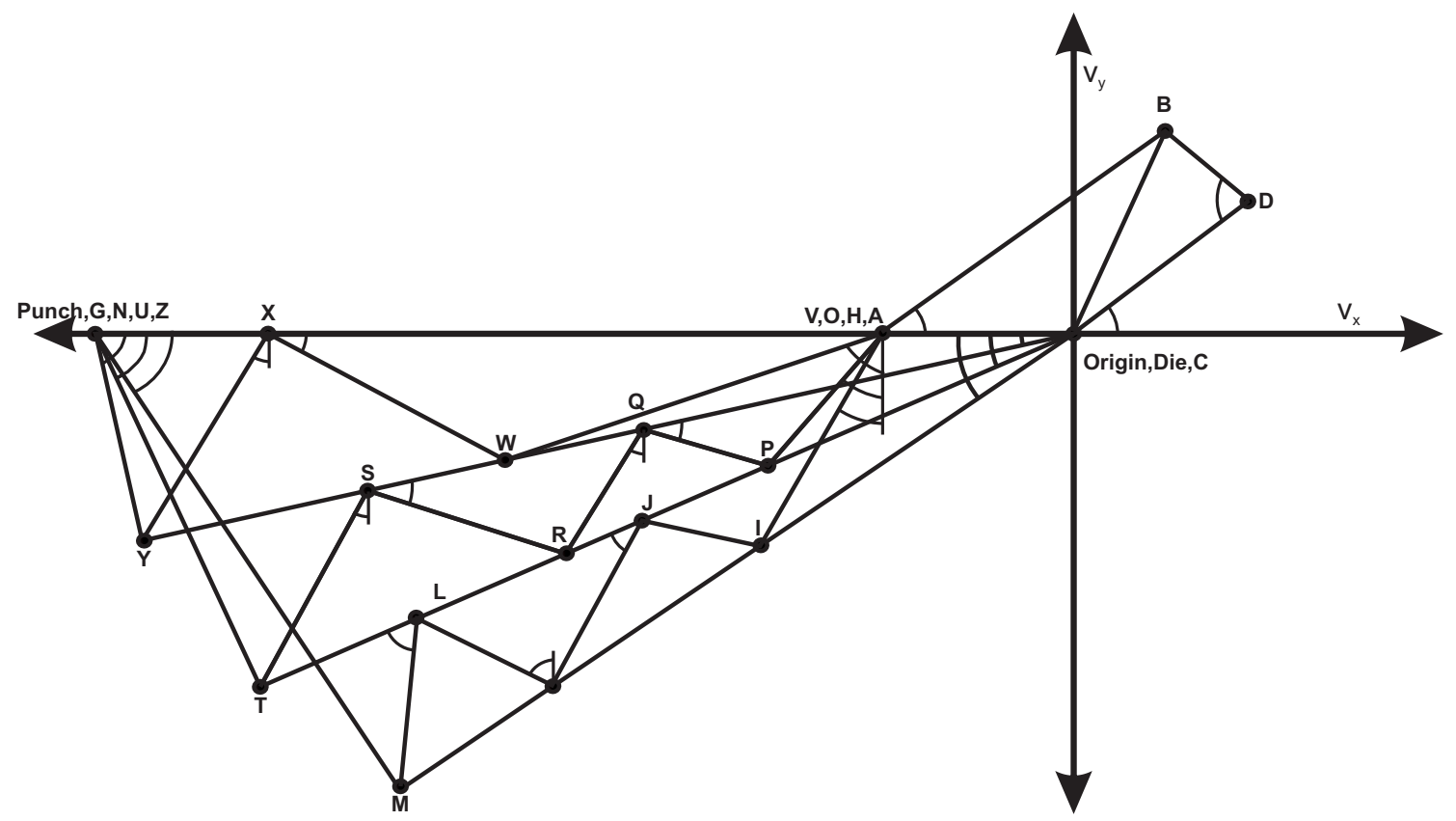

Fig. 8 Hodograph for shaving condition. 